\title{
How to save drug users' lives
}

\author{
Richard Hurley features and debates editor
}

The BMJ

Scotland remains the drug overdose capital of Europe, the latest data show (BMJ doi:10.1136/bmj.14731). Last year 1187 people there died from drug poisoning, more than ever before, up $27 \%$ from 2017 and more than double the count in 2008.

Opioids such as heroin are implicated in more than four in five of these deaths, and HIV rates have rapidly risen among Scottish drug injectors (Lancet doi:10.1016/S2352-3018(19)30036-0).

The US too is experiencing an epidemic of overdose, with more than 70000 deaths from opioid poisoning in 2017 (https://www. cdc.gov/opioids).

Such statistics represent the tip of an iceberg of harm affecting not just people who take drugs but also their families and communities.

The United Nations agency charged with monitoring countries' drugs policy acknowledged in a sea change in 2016 that Portugal's model to prioritise public health instead of criminalising people who take drugs represents the best practice (BMJ doi:10.1136/bmj.i2474). Portugal decriminalised all non-violent, personal drug use in 2001. Deaths of drug injectors have fallen (Drug and Alcohol Review doi:10.1111/j.1465-3362. 2011.00383.x)

This year all UN bodies, including the World Health Organization, called for the decriminalisation of all drug use (https://www.unsceb.org/CEBPublicFiles/CEB-2018-2-SoD. pdf). The Royal College of Physicians and the BMA have similar policies (BMJ doi:10.1136/bmj.k1832; http://bit.ly/ 2yHUmdS). The BMJ supports these calls (doi:10.1136/bmj. i6067).

Such policy shift alone is not enough, but it can make it easier to provide other health promoting interventions.
All harm reduction strategies were originally controversial. Provision of clean needles and syringes, and treatment for opioid dependency with methadone or buprenorphine, are among those that have been proved effective and are now recommended and accepted in the UK. But other potentially helpful interventions remain banned.

The devolved Scottish government wants to follow countries such as Portugal by opening "drug consumption rooms," where people inject their own drugs under medical supervision, with access to lifesaving naloxone as well as education and treatment, as Melanie Newman describes (doi:10.1136/bmj.14906). But drug policy is not a devolved matter, and the UK government has said that opening the rooms would breach UK law, she writes, despite support from its own independent drug advisers and some police commissioners.

Several other jurisdictions worldwide permit such facilities, but evidence on their effect, especially in the long term, is lacking. Proponents point out that no one has died injecting drugs in such a facility. Opponents suggest that the rooms could encourage drug taking, arguments that used to be made against now established harm reduction activities, Newman finds.

Few experts consider that criminalising vulnerable and marginalised people who inject drugs is an appropriate response. The UK government should stop politicking about being "tough on drugs" and act urgently to stop the harm to which its policy contributes. Decriminalisation of personal drug use allows interventions such as safer injecting rooms and drug testing where appropriate. It also enables gathering of evidence.

What is already clear is that moralising about perceived intrinsic wrongs in taking drugs and blaming or punishing patients for having drug use disorders are not effective or ethical ways to reduce harm. 